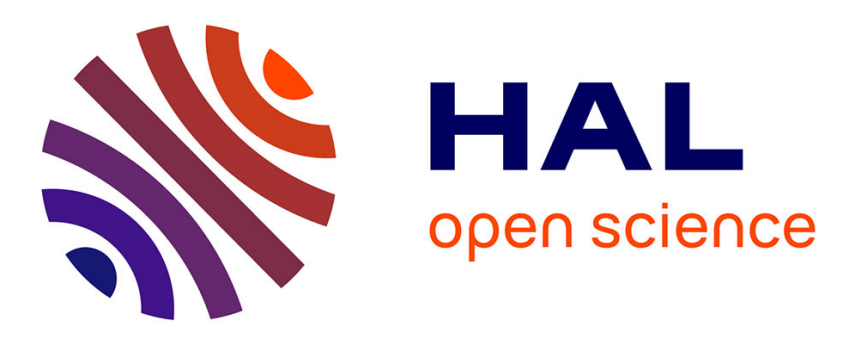

\title{
Indoor residential exposure to semivolatile organic compounds in France
}

Maud Pelletier, Nathalie Bonvallot, Olivier Ramalho, Corinne Mandin, Wenjuan Wei, Gaëlle Raffy, Fabien Mercier, Olivier Blanchard, Barbara Le Bot, Philippe Glorennec

\section{To cite this version:}

Maud Pelletier, Nathalie Bonvallot, Olivier Ramalho, Corinne Mandin, Wenjuan Wei, et al.. Indoor residential exposure to semivolatile organic compounds in France. Environment International, 2017, 109, pp.81-88. 10.1016/j.envint.2017.08.024 . hal-01635777

\section{HAL Id: hal-01635777 https://hal.science/hal-01635777}

Submitted on 15 Nov 2017

HAL is a multi-disciplinary open access archive for the deposit and dissemination of scientific research documents, whether they are published or not. The documents may come from teaching and research institutions in France or abroad, or from public or private research centers.
L'archive ouverte pluridisciplinaire HAL, est destinée au dépôt et à la diffusion de documents scientifiques de niveau recherche, publiés ou non, émanant des établissements d'enseignement et de recherche français ou étrangers, des laboratoires publics ou privés. 
3 Maud Pelletier ${ }^{1,2}$, Nathalie Bonvallot ${ }^{1,2}$, Olivier Ramalho ${ }^{3}$, Corinne Mandin $^{3}$, Wenjuan Wei ${ }^{3}$,

4 Gaëlle Raffy ${ }^{1,2,4}$, Fabien Mercier ${ }^{1,2,4}$, Olivier Blanchard ${ }^{1,2}$, Barbara Le Bot ${ }^{1,2,4}$, Philippe

5 Glorennec $^{1,2^{*}}$

6

$7 \quad{ }^{1}$ EHESP-School of Public Health, Sorbonne Paris Cité, Rennes, France

$8{ }^{2}$ INSERM-U1085, Irset-Research Institute for Environmental and Occupational Health,

9 Rennes, France

$10{ }^{3}$ University of Paris-Est, Scientific and Technical Center for Building (CSTB), Health and

Comfort Department, French Indoor Air Quality Observatory (OQAI), 84 Avenue Jean

Jaurès, Champs sur Marne, 77447 Marne la Vallée Cedex 2, France

${ }^{4}$ LERES-Environment and Health Research Laboratory (Irset and EHESP Technologic

Platform), Rennes, France

*Corresponding author:

INSERM-U1085, Irset-Research Institute for Environmental and Occupational Health,

Rennes, France. EHESP-School of Public Health, Sorbonne Paris Cité, Rennes, France.

Tel.: +33-2 99022680 .

E-mail address: philippe.glorennec@ehesp.fr 
KEY WORDS

Aggregate exposure; cumulative exposure; chemicals; Monte Carlo simulation; indoor air quality; dermal exposure.

\section{ABSTRACT}

Multiple chemicals are emitted in residential accommodation. Aggregate Daily Doses (ADD) (ng/kg-bw/d) were estimated for 32 semivolatile organic compounds (SVOCs) of different chemical families that are frequently detected in French dwellings in both air and settled dust. Daily doses were determined using steady-state models for the population, categorized into 11 age groups covering birth to age 30 . Three routes of exposure were taken into account: dust ingestion, inhalation (gaseous and particulate phases) and dermal contact with the gaseous phase of air. Contamination levels were preferentially retrieved from large, nationwide representative datasets. A two-dimensional probabilistic approach was used to assess parametric uncertainty and identify the most influential factors. For children aged 2 to 3 years, ADD estimates spanned orders of magnitude, with median values ranging from $8.7 \mathrm{pg} / \mathrm{kg}$ bw/d for 2,2',3,4,4'-pentabromodiphenylether (BDE 85) to $1.3 \mu \mathrm{g} / \mathrm{kg}$-bw/d for di-isobutyl phthalate (DiBP). Inhalation, ingestion and dermal pathway contributed at varying levels, and depending on compound, air was the dominant medium for 28 of the 32 compounds (either by inhalation or dermal contact). Indoor exposure estimate variance was mainly driven by indoor contamination variability, and secondarily by uncertainty in physical and chemical parameters. These findings lend support to the call for cumulative risk assessment of indoor SVOCs. 
42

43

44

Both consumer product use and the production of chemicals have been rising constantly since the mid $-20^{\text {th }}$ century, and many of these chemicals are semivolatile organic compounds (SVOCs). SVOCs include compounds from various chemical families: phthalates, bisphenols, polycyclic aromatic hydrocarbons (PAHs), organophosphorus (OPs), organochlorines (OCs), synthetic musks, polychlorinated biphenyls (PCBs) and polybromodiphenylethers (PBDEs).

The health effects of SVOCs have been assessed by numerous studies on both humans and animals; some are suspected of having reprotoxic (Casas et al. 2013; Rubin 2011), neurotoxic (Baldi et al. 2001; Blanc-Lapierre et al. 2012; Elbaz et al. 2009; Zaganas et al. 2013) or carcinogenic effects (Armstrong et al. 2004; IARC 2010a, 2010b).

SVOCs are emitted by volatilization from their source materials and contaminate other compartments; in some cases, they can also migrate directly from source (Sukiene et al. 2017). In the indoor environment, they are found in the gas phase, airborne particles, settled dust (Weschler and Nazaroff 2008) and on any other available surfaces such as walls, ceiling and flooring - as well as on human skin and clothing. In addition to dietary exposure and dermal contact with consumer products, humans are continuously exposed to these chemicals through various pathways, including inhalation of indoor air (gaseous and particulate phases), ingestion of settled dust and dermal contact with indoor air and settled dust (on floor and other surfaces). Many authors have assessed indoor exposure to certain families of SVOCs (phthalates, PBDEs, etc.), taking into account one or more exposure media via oral, respiratory (and sometimes dermal) pathways (Bekö et al. 2013; Gaspar et al. 2014; Linares et al. 2010; Mitro et al. 2016; Roosens et al. 2010; Trudel et al. 2011; Wilson et al. 2003). Mitro et al. (2016) recently estimated indoor exposures based on US dust surveys and an air 
contamination model. Here, we seek to use measurement data to assess the exposure of a large population and estimate the associated uncertainty.

The objective of this study was to estimate the indoor exposure of people of various age groups, to 32 SVOCs from different chemical families frequently detected in French dwellings (Blanchard et al. 2014; Mandin et al. 2014, 2016). Three routes of exposure were taken into account: dust ingestion, inhalation of air (gaseous and particulate phases) and dermal contact with the gaseous phase of air. Contamination levels were preferentially retrieved from large, representative datasets. A two-dimensional probabilistic approach was used to assess the uncertainty associated with the different parameters, and identify the most impacting factors.

\section{METHODS}

Target Population: To address exposure across a broad section of the population, we estimated exposures for 11 age groups from birth to age 30 (as an example of an adult), following the U.S. Environmental Protection Agency (U.S. EPA 2005) recommendations as to which age groups should be considered within a health risk assessment.

Compounds selection: 32 SVOCs were selected on the basis of their health interest (Bonvallot et al. 2010), and because they were detected in both the air and the settled dust of French dwellings (Blanchard et al. 2014; Mandin et al. 2014, 2016).

Exposure model: The Aggregate Daily Doses (ADD) (ng/kg-bw/d) were assessed by summing internal (uptake) daily doses from dust ingestion $\left(\mathrm{DD}_{\text {ing-dust }}\right)$, inhalation of air (both gaseous and particulate phases) $\left(\mathrm{DD}_{\text {inh-air }}\right)$ and dermal contact with gas phase $\left(\mathrm{DD}_{\text {derm-gas }}\right)$.

Very few studies included the dermal exposure to dust pathway when assessing aggregate exposures to SVOCs. Trudel et al. (2011) studied dermal exposure to 8 PBDEs in dust. Even 
though they overestimated this pathway using in vitro experimental data with acetone as carrier vehicle (Roper et al. 2006), they found the contribution of dermal exposure to dust to be consistently $<20 \%$, even for the most contaminated region, and for every age group (below 1 year to 65 years of age). Bekö et al. (2013) estimated indoor exposure to five phthalates and found a very low $(<1 \%)$ contribution of dermal exposure to dust, in comparison to other pathways. Since this pathway is typically found to be minor and required uptake parameters are ill-suited to dust exposure even when available, dermal exposure to dust was not addressed in this work.

Equations for exposure dose estimation: Daily Doses (DD) can be estimated in steady-state conditions using the following equations. These were adapted from relationships developed by Bekö et al. (2013) and Weschler and Nazaroff (2012, 2014).

\section{Ingestion of settled dust}

$$
D D_{\text {ing-dust }}=\frac{C_{d u s t} \times D I \times f_{\text {oral }} \times f_{\text {dust }} \times t}{B W}
$$

Where $\mathrm{C}_{\text {dust }}$ is the SVOC concentration in settled dust (ng/g), DI is the amount of dust ingested by an individual per day $(\mathrm{g} / \mathrm{d}), \mathrm{f}_{\text {oral }}$ is the oral bioavailability of the $\operatorname{SVOC}(-), \mathrm{f}_{\text {dust }}$ is the bioaccessibility of the SVOC from the dust (-), $t$ is the fraction of time spent in dwellings $(-), \mathrm{BW}$ is the body weight $(\mathrm{kg})$, and $\mathrm{DD}_{\text {ing-dust }}$ is expressed in $\mathrm{ng} / \mathrm{kg}-\mathrm{bw} / \mathrm{d}$.

$\underline{\text { Inhalation of indoor air }}$

$$
D D_{\text {inh-air }}=\frac{\left(C_{\text {part }}+C_{\text {gas }}\right) \times I R \times f_{\text {pulm }} \times t}{B W}
$$

Where $\mathrm{C}_{\text {part }}$ is the SVOC particulate phase concentration $\left(\mathrm{ng} / \mathrm{m}^{3}\right), \mathrm{C}_{\mathrm{gas}}$ is the SVOC gas phase concentration $\left(\mathrm{ng} / \mathrm{m}^{3}\right)$, IR is the inhalation rate for an individual per day $\left(\mathrm{m}^{3} / \mathrm{d}\right), \mathrm{f}_{\text {pulm }}$ is the 
pulmonary bioavailability of the SVOC (-), $t$ is the fraction of time spent in dwellings (-), BW is the body weight $(\mathrm{kg})$, and $\mathrm{DD}_{\text {inh-air }}$ is expressed in $\mathrm{ng} / \mathrm{kg}-\mathrm{bw} / \mathrm{d}$.

\section{Dermal contact with the gas phase}

$$
D D_{\text {derm-gas }}=\frac{C_{g a s} \times k_{p-g} \times B S A \times t}{B W}
$$

Where $\mathrm{C}_{\mathrm{gas}}$ is the SVOC gas phase concentration $\left(\mathrm{ng} / \mathrm{m}^{3}\right), \mathrm{k}_{\mathrm{p}-\mathrm{g}}$ is the SVOC transdermal permeability coefficient $(\mathrm{m} / \mathrm{h})$, BSA is the body surface area $\left(\mathrm{m}^{2}\right), \mathrm{t}$ is the daily duration exposure $(\mathrm{h} / \mathrm{d}), \mathrm{BW}$ is the body weight $(\mathrm{kg})$, and $\mathrm{DD}_{\text {derm-gas }}$ is expressed in $\mathrm{ng} / \mathrm{kg}-\mathrm{bw} / \mathrm{d}$. The steady-state model adapted by Weschler and Nazaroff $(2012,2014)$ used to estimate $\mathrm{k}_{\mathrm{p}-\mathrm{g}}$ is described in more detail in Supplemental Material (see S1). This requires use of the SVOC octanol/water partition coefficients $\left(\log \left(\mathrm{K}_{\mathrm{ow}}\right)\right)$, Henry's law constants $(\mathrm{H})$ and coefficients describing the external transport of a gaseous SVOC from the bulk indoor air to the boundary layer adjacent to the skin $\left(\mathrm{Yd}_{\mathrm{d}}\right)$.

The ADD for a single SVOC for an individual was then calculated by summing the previous doses according to the following equation, and expressed in $\mathrm{ng} / \mathrm{kg}-\mathrm{bw} / \mathrm{d}$ :

$$
A D D=D D_{\text {ing-dust }}+D D_{\text {inh-air }}+D D_{\text {derm-gas }}
$$

Parameter estimation for exposure model: Parameter distributions were constructed or retrieved from the literature as detailed below. Some of these parameters will be the same for all SVOCs ( $\mathrm{yd}_{\mathrm{d}}, \mathrm{BW}, \mathrm{BSA}, \mathrm{IR}, \mathrm{DI}$ and $\left.\mathrm{t}\right)$ while others will vary from one compound to another $\left(\mathrm{f}_{\text {oral }}, \mathrm{f}_{\text {dust }}, \mathrm{f}_{\text {pulm }}, \log \left(\mathrm{K}_{\text {ow }}\right), \mathrm{H}, \mathrm{C}_{\text {dust }}, \mathrm{C}_{\text {part }}\right.$ and $\left.\mathrm{C}_{\text {gas }}\right)$. 
127 For each SVOC, measured or estimated values of $\log \left(\mathrm{K}_{\mathrm{ow}}\right)$ and $\mathrm{H}$ at $25^{\circ} \mathrm{C}$ were retrieved 128 from: online databases - Hazardous Substances Data Bank (HSBD) and ChemIDplus 129 (http://toxnet.nlm.nih.gov/), Chemspider (http://www.chemspider.com/), and Chemicalize 130 (http://www.chemicalize.org/); toxicological and environmental data sheets from the French 131 National Competence Center for Industrial Safety and Environmental Protection (INERIS) 132 (http://www.ineris.fr/substances/fr/page/21); online calculators - Chemexper (https://www.chemexper.com/) and ACD/Labs (http://www.acdlabs.com/); EPI Suite software (U.S. EPA, v4.1) and the Handbook of Physical-Chemical Properties and Environment Fate for Organic Chemicals (Mackay et al. 2010a, 2010b, 2010c, 2010d). Particular attention was paid to avoiding duplicates (EPI Suite software, HSBD and ChemIDplus often used the same sources for these parameters). Furthermore, only values at the reference temperature of $25^{\circ} \mathrm{C}$ were selected, in order to obtain comparable data between compounds and estimate DD at a constant temperature. At least two values were available for each SVOC. Where at least 15 values for $\log \left(\mathrm{K}_{\mathrm{ow}}\right)$ and $\mathrm{H}$ were available, distributions were fitted. Otherwise, we used either triangular distributions having at least three values (minimum, average and maximum), or uniform distributions for two retrieved values. See Table S1 for corresponding distributions and input parameters for each SVOC.

\section{$\underline{\text { Contamination data }}$}

Contamination data were provided from measurements taken in recent French housing surveys. Concentration levels in settled dust collected from vacuum cleaner bags were retrieved from a national survey covering the 3.6 million French dwellings that were home to at least one child aged 6 months to 6 years in 2008-2009, using 145 samples (Mandin et al. 2014). Concentration levels in airborne Particulate Matter (PM) of $10 \mu \mathrm{m}$ in diameter were retrieved from a national survey covering the 24.7 million French main residences, using 285 
period of one week, and assumed to be representative of each dwelling as a whole. SVOC gas phase concentrations were not available at national scale; data from 30 French dwellings (Blanchard et al. 2014) were used as a surrogate.

Modeling was established regarding the percentage of samples above the limit of detection (LOD) or the limit of quantification (LOQ) for the retrieved studies. For settled dust and PM measurements, lognormal distributions were fitted using summary statistics when $>75 \%$ of data were above LOD (Burmaster 1997). This concerns 20 and 14 compounds, for settled dust and PM measurements respectively. Where detection frequency ranged from 20 to $75 \%$, the maximum-likelihood estimation (MLE) was used to estimate lognormal distributions (Helsel 2011; Helsel and Hirsch 1992). This statistical method could be used to estimate the undetected data in the studies of Mandin et al. (2014, 2016), because sample sizes were large enough - with 145 and 285 samples for dust and PM respectively. The number of compounds concerned was 7 for settled dust and 11 for PM measurements. Where detection frequency ranged from 1 to $20 \%$, custom distribution was modeled with discrete probability for the quantified values, and continuous uniform probability from 0 to LOD and from LOD to LOQ. The number of compounds concerned was 5 for settled dust and 7 for PM measurements. For the gas phase measurements, the Blanchard et al. (2014) sample size $(n=30)$ was too small to use MLE. So, where detection frequency ranged from 1 to $99 \%$, custom distribution was modeled using continuous uniform probability from 0 to LOQ and discrete probability for the quantified values. For all three media, a literature survey was conducted to retrieve specific data when detection frequency was $<1 \%$. Publications were selected in the following order of preference: conducted in Europe, post-2000 and providing sample size, measurement method, LOD and/or LOQ values and percentage of samples above the LOD and/or LOQ. Where a lower LOD or LOQ was used, other contamination information was used instead of the 
initially-selected data (Blanchard et al. 2014; Mandin et al. 2014, 2016). See Table S2 for corresponding distributions and input parameters for each SVOC in each medium.

\section{Exposure media properties}

Assessment of $\mathrm{DD}_{\text {derm-gas }}$ (Eq. 3) requires use of a transdermal permeability coefficient, $\mathrm{k}_{\mathrm{p}-\mathrm{g}}$, estimated using the specific physical and chemical parameters of each SVOC, and a nonspecific mass transport coefficient, $\mathrm{\gamma}_{\mathrm{d}}$. This last describes the external transport of an SVOC from the gas phase in the core of a room through the boundary layer adjacent to the skin, see Eq. 1 (Supplemental Material). A triangular distribution was modeled for $\mathrm{y}_{\mathrm{d}}$, using the minimum and maximum values found in the literature and the generally assumed value of 6 $\mathrm{m} / \mathrm{h}$ as most likely (Pandrangi and Morrison 2008; Tamas et al. 2006; Weschler and Nazaroff 2008). See Table S3 for corresponding distribution and input parameters.

\section{$\underline{\text { Bioaccessibility and bioavailabilities }}$}

Bioaccessibility in dust $\left(f_{\text {dust }}\right)$ is the fraction of pollutant released from settled dust into the gastrointestinal tract and available for absorption (Rostami and Juhasz 2011). For each SVOC, $\mathrm{f}_{\text {dust }}$ was retrieved from the literature survey performed by Raffy et al. (2016). Oral bioavailability $\left(\mathrm{f}_{\text {oral }}\right.$ ) is the fraction of a contaminant reaching the digestive system and absorbed into systemic circulation (Rostami and Juhasz 2011). Pulmonary bioavailability $\left(f_{\text {pulm }}\right)$ is the fraction of a contaminant reaching the alveolar system and absorbed into systemic circulation. For each SVOC, $\mathrm{f}_{\text {oral }}$ and $\mathrm{f}_{\text {pulm }}$ were retrieved from the following online databases: the HSBD (https://toxnet.nlm.nih.gov/cgi-bin/sis/htmlgen?HSDB) and the Agency for Toxic Substances and Disease Registry (ATSDR) (https://www.atsdr.cdc.gov/). For each compound displaying at least three available values, triangular distributions were modeled (minimum, average and maximum values). Where only two values were retrieved, uniform distributions were modeled (minimum and maximum). Where only a single value was 
available, triangular distributions were modeled between this value (as the likeliest), and the minimum and the maximum values retrieved from other compounds belonging to the same chemical family. Finally, if no value was found for an SVOC, a uniform distribution was modeled between the minimum and the maximum values found for the other compounds from the same chemical family - or from the entire studied chemical families taken together if no other compound from the same chemical family was assessed. See Table S4 for corresponding distributions and input parameters for each SVOC.

\section{$\underline{\text { Human body parameters }}$}

The World Health Organization (WHO 2006) has identified and suggested common critical life stages for use in exposure and risk assessment. Because these were not available for every parameter and age group for populations living in France, we used the U.S. EPA Exposure Factors Handbook (U.S. EPA 2011). The potential influence of this is covered in the discussion section. We compiled the distribution of human body weight (BW), body surface area (BSA), dust ingestion (DI), inhalation rate (IR) and time spent in dwellings (t). Lognormal distributions were used for BW, BSA and DI. Normal distributions were used for IR and t. See Table S5 for corresponding distributions and input parameters.

Simulation: DD from all three routes of exposure (Eq. 1 to 3) and ADD (Eq. 4) were estimated using Crystal Ball ${ }^{\circledR}$ software $\left(\right.$ Oracle $^{\circledR}$, version 11.1.1.3.00). Latin Hypercube twodimensional simulations were carried out with 500,000 runs for each SVOC, and each age group. Two-dimensional simulations take into account both the uncertainty (lack of knowledge about a parameter) and the variability (heterogeneity of a parameter in a population) of the input parameters. The following parameters were considered variable (i.e. high variability in relation to uncertainty): $\mathrm{C}_{\text {dust }}, \mathrm{C}_{\text {part }}, \mathrm{C}_{\mathrm{gas}}, \mathrm{\gamma}_{\mathrm{d}}, \mathrm{BW}, \mathrm{BSA}, \mathrm{IR}$ and $\mathrm{t}$, whereas $\log \left(\mathrm{K}_{\mathrm{ow}}\right), \mathrm{H}, \mathrm{f}_{\text {oral }}, \mathrm{f}_{\text {dust }}$ and $\mathrm{f}_{\text {pulm }}$, were considered uncertain. DI was considered both uncertain 
and variable. Sensitivity analysis was performed in a one-dimensional simulation by assessing the contribution of each input parameter to ADD variance (the output), using linear regression.

\section{RESULTS}

\section{[Figure 1]}

ADD (ng/kg-bw/d) estimates for the 32 SVOCs for children aged 2 to 3 years are shown in Figure 1. We are presenting results for this specific segment because young children are more vulnerable than the rest of the population in terms of exposure to contaminants (due to more frequent contact with the ground and deposited dust, carrying objects in their mouths, higher inhalation rates, etc.) and more sensitive in terms of effects (due to ongoing development of the main organ systems, which continues after birth). Detailed results for ADD and the three DD from each exposure route for all 11 age groups (birth to age 30) are shown in Tables S8 to S18. ADD estimations spanned orders of magnitude, with median values ranging from 8.7 $\mathrm{pg} / \mathrm{kg}$-bw/d for 2,2',3,4,4'-pentabromodiphenylether (BDE 85) to $1.3 \mu \mathrm{g} / \mathrm{kg}-\mathrm{bw} / \mathrm{d}$ for diisobutyl phthalate (DiBP) for children aged 2 to 3 years. Variability of ADD (relative interpercentile range, see Table S6) ranged from 1.2 for 2,2',4,4',5-pentabromodiphenylether (BDE 99) to 12 for 2,3,3',4,4'-pentachlorobiphenyl (PCB 105), with a median value of 4. The median uncertainty on the mean was $40 \%$, ranging from $11 \%$ for the benzo[a]pyrene to $230 \%$ for 2,3',4,4',5-pentachlorobiphenyl (PCB 118) (see detailed relative errors in Table S13).

The relative contribution of exposure pathways to aggregated median exposure is presented in Figure 1 (bottom panel) for children aged 2 to 3 years. The relative contributions made by each route of exposure to total indoor estimates differ by compound, and could be related to their degree of volatility. For the most volatile SVOCs - that is those compounds having an octanol-air partition coefficient $\left(\log \left(\mathrm{K}_{\mathrm{oa}}\right)\right)$ value of 9 or less (see Table $\mathrm{S} 1$ ) and expected to be 
primarily gaseous (Weschler and Nazaroff, 2012), inhalation and dermal contact with the gas phase were the dominant routes of exposure: fluorene, anthracene, aldrin, dieldrin, tonalide, galaxolide, tributylphosphate, diethyl phthalate (DEP), dibutyl phthalate (DBP), DiBP and 2,4,4'-trichlorobiphenyl (PCB 28), 2,4',5-trichlorobiphenyl (PCB 31) and 2,2',5,5'tetrachlorobiphenyl (PCB 52). For less volatile SVOCs - that is those compounds having a log $\left(\mathrm{K}_{\mathrm{oa}}\right)$ value of 13 or greater (see Table $\mathrm{S} 1$ ) and expected to be primarily in the particle phase (Weschler and Nazaroff, 2012), dust ingestion was the dominant route of exposure: diethylhexyl phthalate (DEHP), di-isononyl phthalate (DiNP) and 2,2',4,4',5,6'hexabromodiphenylether (BDE 154). The contribution made by different pathways was more contrasted for SVOCs having a $\log \left(\mathrm{K}_{\mathrm{oa}}\right)$ value of between 9 and 13 (see Table $\mathrm{S} 1$ ). On the whole, air was the dominant exposure medium (sum of inhalation and dermal contact $>50 \%$ of ADD) for 28 compounds out of 32, while dust was the major contributor for DEHP, DiNP, benzyl butyl phthalate (BBP) and 2,2',4,5,5'-pentachlorobiphenyl (PCB 101). Overall, dust ingestion is more contributive to exposure for less volatile chemicals, although this is not the case with BBP and PCB 101, both of which are found in relatively high concentrations in dust.

Relative contributions of exposure pathways for P95 values were similar to median values. Notable exceptions were that higher contributions from dust ingestion were found for PCB 118, 2,2',3,4,4',5'-hexachlorobiphenyl (PCB 138) and 2,2',4,4',5,5'-hexachlorobiphenyl (PCB 153), and higher contributions from inhalation were found for benzo[a]pyrene and DBP.

[Figure 2]

The main sensitivity analysis results are shown in Figure 2 (see Table S7 for detailed results). These reveal that contamination parameters are most influential: $\mathrm{C}_{\mathrm{gas}}, \mathrm{C}_{\mathrm{part}}$ and $\mathrm{C}_{\text {dust }}$, the only exception being $\mathrm{H}$ for $\mathrm{BDE}$ 99. Their relative contributions to ADD variance ranged from 
$27230 \%$ for galaxolide $\left(\mathrm{C}_{\mathrm{part}}\right)$ and BDE $99(\mathrm{H})$ to $89 \%$ for fluorene $\left(\mathrm{C}_{\mathrm{gas}}\right)$. For most compounds, 273 the other influential parameters (having contributions higher than 10\%) are the other

274 contamination parameters: $\mathrm{C}_{\text {gas }}, \mathrm{C}_{\text {part }}$ and $\mathrm{C}_{\text {dust }}$, and also $\mathrm{f}_{\text {pulm. }}$. For some compounds, other 275 influential parameters are $\mathrm{f}_{\text {dust }}$ (DEHP and DiNP) alongside physical and chemical 276 parameters: $\log \left(\mathrm{K}_{\mathrm{ow}}\right)$ and $\mathrm{H}$ (lindane and BDE 99). Furthermore, compounds have been 277 ranked by volatility in Figure 2 (based on their $\log \left(\mathrm{K}_{\mathrm{oa}}\right)$ values), from most volatile (fluorene) 278 to least volatile (DiNP). Among the most volatile SVOCs, $\mathrm{C}_{\mathrm{gas}}$ tended to be the more 279 influential parameter, while $\mathrm{C}_{\text {dust }}$ and $\mathrm{C}_{\text {part }}$ appeared influential for the least volatile. Lastly, 280 we note that within each age group, human parameters were not influential.

ADD (ng/kg-bw/d) estimates for the 32 SVOCs for four age groups are shown in Figure 3: infants aged 0 to 1 months, infants aged 1 to 3 months, children aged 2 to 3 years and adults aged 21 to 30 years. As expected, ADD decreases with age because of increasing BW - except within the [0-1 month] category where the dust ingestion rate equals $0 \mathrm{mg}$, and ADD may be lower in comparison with other groups. This is true in particular of compounds making a major contribution to dust ingestion (PCB 101, BBP, DEHP and DiNP). Detailed results for ADD across all 11 age groups (birth to age 30) are shown in Tables S8 to S18.

\section{DISCUSSION}

Indoor exposure to 32 SVOCs was modeled using contamination measurements from dwellings and human body parameters. ADD spanned orders of magnitude from $8.7 \mathrm{pg} / \mathrm{kg}$ -

$292 \mathrm{bw} / \mathrm{d}$ to $1.3 \mu \mathrm{g} / \mathrm{kg}-\mathrm{bw} / \mathrm{d}$. Inhalation, ingestion and dermal pathway all contributed, though differently across compounds. Indoor exposure estimations were influenced more by variability in indoor concentrations $\left(\mathrm{C}_{\mathrm{gas}}, \mathrm{C}_{\text {part }}\right.$ and $\left.\mathrm{C}_{\mathrm{dust}}\right)$ than by uncertainty in physical and chemical parameters. 
Study strengths include: 1) estimation of indoor exposure to numerous SVOCs from different chemical families via gas- and particle-phase inhalation, dermal contact with gas phase, and ingestion of settled dust; 2) use of field measurements in dust, particulate and gaseous phases; 3) use, when available, of large and nationwide representative datasets; 4) choice of a twodimensional probabilistic approach, and 5) consideration of many age groups.

Study limitations include: 1) use of an exposure model that neglects dynamic conditions; 2) use of different data sets for different exposure media, and 3) uncertainty analysis being restricted to parameter uncertainty.

We used steady-state models to estimate indoor exposure to SVOCs. Because indoor air measurements were performed over a period of one week, and settled dust being collected in a vacuum cleaner, we assumed that equilibrium had been reached. Because we frequently move from one environment into another, or between rooms having different concentrations, equilibrium is rarely achieved for the transfer from air to skin. A transient model developed by Gong et al. (2014) considered convective mass transfer resistance in the boundary air layer adjacent to the skin. Morrison et al. (2016) have recently improved this model by including skin surface lipids, which increase overall resistance to SVOC uptake from air. However, because these models require parameters that are not available for all compounds, default parameters are employed - rendering a probabilistic assessment difficult.

For contamination data in the three media when the detection frequency was $<1 \%$ (Blanchard et al. 2014; Mandin et al. 2014, 2016) a literature survey was conducted to retrieve other contamination information, which was then employed (instead of the initially-targeted data) where a lower LOD or LOQ was used by the authors (see Table S2). This concerned settled dust and gas phase concentrations for the 2,4,4'-tribromodiphenylether (BDE 28), and gas phase concentration alone for 12 other SVOCs: benzo[a]pyrene, PCB 31, PCB 105, PCB 118, 
PCB 138, PCB 153, BDE 47, BDE 85, BDE 99, 2,2',4,4',6-pentabromodiphenylether (BDE 100), 2,2',4,4',5,5'-hexabromodiphenylether (BDE 153) and BDE 154.

To put our results into perspective, this indoor aggregate multimedia and multipathway exposure assessment was compared to the few other studies investigating the same exposure pathways, namely: Bekö et al. (2013), Gaspar et al. (2014) and Mitro et al. (2016), who investigated phthalates and galaxolide for children aged 3 to 6 years in Denmark, California (US) and 14 states of the US, respectively. Our ADD estimated median values for children aged 3 to 6 years (see Table S14) were compared to: estimated median values for DBP and DEHP (Bekö et al. 2013; Gaspar et al. 2014); estimated median values for DiBP, BBP and DEP (Bekö et al. 2013), and estimated average values for DBP, DEHP, DiBP, BBP, DEP and galaxolide (Mitro et al. 2016). Similar results were found for DBP, DEHP and DEP. For DiBP, we found a median value equal to $1.1 \mu \mathrm{g} / \mathrm{kg}$-bw/d, consistent with the $1.5 \mu \mathrm{g} / \mathrm{kg}$-bw/d found by Bekö et al. (2013). Using a dust contamination level for this compound that was seven times lower, Mitro et al. (2016) found a lower exposure level equal to $0.1 \mu \mathrm{g} / \mathrm{kg}$-bw/d. This difference in concentration data between French and US samples may also reflect a shift in the use of phthalates as a result of changes to the formulation of plasticizers. For BBP, we found a median value equal to $0.1 \mu \mathrm{g} / \mathrm{kg}$-bw/d, consistent with the $0.2 \mu \mathrm{g} / \mathrm{kg}$-bw/d of Mitro et al. (2016). Using a dust contamination level for this compound that was four times lower, Bekö et al. (2013) found a lower exposure level equal to $0.01 \mu \mathrm{g} / \mathrm{kg}-\mathrm{bw} / \mathrm{d}$. Regarding galaxolide, our exposure level of $0.05 \mu \mathrm{g} / \mathrm{kg}$-bw/d is consistent with Mitro et al. (2016) who found $0.1 \mu \mathrm{g} / \mathrm{kg}$-bw/d - in line with dust contamination that was twice as high as ours.

Pathway contributions were found to be similar to Mitro et al. (2016) for DBP, DEP and galaxolide, with inhalation as the main route of exposure (>50\%), followed by dermal absorption from the gas phase and dust ingestion. Pathway contribution estimates from Bekö et al. (2013) for DiBP, BBP and DEHP are also similar to our findings, with total uptake 
dominated by dermal absorption from the gas phase for DiBP, and dust ingestion for BBP and DEHP. The results of the present study were also comparable to Gaspar et al. (2014), with dust ingestion dominating total uptake of DEHP.

In addition to the indoor exposure in dwellings assessed by this study, other sources of exposure (e.g. diet and personal care products) and other indoor environments (e.g. schools and offices) for many of these compounds contribute to total exposure, as well as direct dermal contact with surfaces. The use of personal care products, directly applied to skin or inhaled from aerosols, could have a non-negligible contribution to total exposure for some compounds, e.g., for certain phthalates (Romero-Franco et al. 2011) and musks (Zhang et al. 2017). Most of the studies addressing SVOC exposure assessment also looked at dietary ingestion (Beamer et al. 2012; Duggan et al. 2003; Lorber et al. 2007; Roosens et al. 2010; Trudel et al. 2011; Wilson et al. 2003; Wormuth et al. 2006). This could naturally lead to higher ADD estimates and different pathway contributions. Diet has been shown to be an important source of exposure for certain compounds: e.g. some PBDEs (Trudel et al. 2011) and some phthalates (Wilson et al. 2003). However, several authors who have performed exposure assessments on both indoor and diet exposure found that dietary ingestion was not the main route of exposure for chlorpyrifos (Beamer et al. 2012; Duggan et al. 2003), DEP, BBP and DiNP (Wormuth et al. 2006), some PBDEs (Lorber et al. 2007), some PCBs and some OCs (Wilson et al. 2003). For certain compounds, exposure via dietary ingestion could also equal exposure via non-dietary ingestion: e.g. DEHP (Wormuth et al. 2006), and anthracene, phenanthrene, benzo[a]pyrene and fluorene (Wilson et al. 2003). To put our results in perspective, we compared them to those of the French infant total diet study (ANSES 2016a, 2016b). We compared to lower bound (LB) and upper bound (UB) median estimates for children aged 2 to 3 years. For 6 PCBs (sum of PCB 28, 52, 101, 138, 153 and 2,2',3,4,4',5,5'-heptachlorobiphenyl (PCB 180)) our median residential indoor ADDs were 
about one order of magnitude lower than dietary exposure estimates (LB and UB). For 7 PBDEs (sum of BDE 28, 47, 99, 100, 153, 154 and 2,2',3,4,4',5',6-heptabromodiphenylether (BDE 183)) they were about one order of magnitude higher (LB and UB). For DEHP they were of the same order of magnitude (LB and UB). For DiNP and lindane they were of the same order of magnitude as the LB estimates and about one order of magnitude lower than the UB. For BBP, DEP and DBP they were of the order of magnitude of UB estimates, and one order of magnitude higher than the LB. For DiBP they were about one or two orders of magnitude higher than UB and LB respectively. For chlorpyrifos, dieldrin and aldrin they were of the same order of magnitude, in comparison with the LB estimates, and about two orders of magnitude lower, in comparison with the UB.

Compared to more traditional deterministic approaches, probabilistic methods (e.g. Monte Carlo simulations) have the main advantage of addressing input parameters featuring both uncertainty and variability. ADD estimations were mainly dependent on variability in indoor concentrations $\left(\mathrm{C}_{\mathrm{gas}}, \mathrm{C}_{\text {part }}\right.$ and $\left.\mathrm{C}_{\mathrm{dust}}\right)$, and secondarily by uncertainty in $\mathrm{f}_{\text {pulm }}$ and physical and chemical parameters. Uncertainty of parameters is related to lack of total knowledge, whereas data variability refers to true heterogeneity. An interesting finding is that although input parameter uncertainty has been accused of causing broad uncertainty in exposure estimates (Pelletier et al. 2017; Salthammer and Schripp 2015), it appeared to contribute less to total variance of ADD than did variability. For every compound but one, variability of a concentration explains at least $40 \%$ of ADD variance; in half of all cases, this exceeded $60 \%$. Concentrations of a chemical within dwellings span orders of magnitude, especially as a result of the presence (or absence) of a source in the dwelling. Physical and chemical parameters can either be measured experimentally or calculated using other chemical properties. Depending on which of these methods is used, it follows that values vary by one order of magnitude or more (Finizio et al. 1997) - and these uncertainties are propagated in the 
calculation of $\mathrm{DD}_{\text {derm-gas }}$ and then $\mathrm{ADD}$. Up to $34 \%$ of $\mathrm{ADD}$ variation for aldrin could be explained by uncertainty in $\mathrm{f}_{\text {pulm }}$ (see Table S7) because data for most of the SVOCs were unavailable. Indeed, data were available for just two compounds: 2,2',4,4'tetrabromodiphenylether (BDE 47) and benzo[a]pyrene, leading to modeling of uniform distribution between 0 and $100 \%$ for most compounds (see Table S4) and to potential overestimation of inhalation exposure. The same limit was encountered for the other uptake fractions ( $f_{\text {oral }}$ and $\left.f_{\text {dust }}\right)$, though to a lesser extent. For most SVOCs, in respect of $f_{\text {oral }}$, even where pharmacokinetics studies were available and provided qualitative evidence that the SVOC was absorbed following oral exposure, no quantitative data describing in vivo oral absorption were available in the literature. Moreover, in laboratory animals, absorption of a compound can also depend strongly on experimental parameters, such as the carrier vehicle employed (Huwe et al. 2008). For example, gastrointestinal lindane bioavailability in rats ranged from $6 \%$ when the compound was suspended in water to $99 \%$ when given in oil. A further aspect is that we used $\mathrm{PM}_{10}$ measurements, whereas a smaller sampling fraction would have been more representative of respirable particles - this may result in an overestimation of the inhalation pathway for those SVOCs mainly present in the particulate phase (BDE 47, BDE 99, benzo[a]pyrene, PCB 118, PCB 138 and PCB 153). Human body parameters (BW, BSA, IR, DI and t) are highly variable and, to a lesser extent, uncertain. Özkaynak et al (2011) found significant uncertainty on DI, and this result led us to consider both uncertainty and variability for this parameter in our study. Nevertheless, we found that human body parameters made a marginal or null contribution (see Table S7) to the variance of ADD for a child aged 2 to 3 years, for each SVOC. It is however important to bear in mind both that we ran the model age-group by age-group, and that these parameters can have a broader impact when applied to a more diverse population. 
Recent studies have investigated and modeled the clothing effect. Morrison et al. (2016) have

420 shown that frequency of bathing and changing clothes were influential in terms of dermal

421

422

423 uptake. In addition, introduction to the model of a skin surface lipid film, and its interactions with clothing, may affect results. The authors assessed the influence of clothing on the dermal uptake of two phthalates (DEP and DBP). They found that clean clothes were protective against air pollutants, whereas worn clothes, because they had adsorbed air pollutants, increased dermal uptake. Because only clean clothes could be considered protective, we decided to not take into account the role of clothing in this study, making the assumption that the total body surface area was exposed to the gaseous phase.

\section{CONCLUSIONS}

This indoor aggregate multimedia and pathway exposure assessment considered a wide range of pollutants, across a broad population. It reveals that exposure spanned orders of magnitude, from $\mathrm{pg} / \mathrm{kg}$-bw/d to $\mu \mathrm{g} / \mathrm{kg}$-bw/d and was mainly dependent on indoor SVOC contaminations.

Within the boundaries of the conceptual model we used, exposure variability overwhelmed its uncertainty. Air was the dominant medium for most compounds, either by inhalation or dermal contact. Along with evidence of these compounds causing similar toxic effects (Fournier at al. 2014; Mitro et al. 2016), these findings lend support to the call for cumulative risk assessment of indoor SVOCs.

Acknowledgments: this work was supported by a doctoral Grant (Maud Pelletier) from Fondation de France (Grant Number 2014-00053331) and Agence de 1'Environnement et de la Maîtrise de l'énergie (Grant Number TEZ14-36). 
442 The authors declare having no competing financial interests. 


\section{REFERENCES}

ANSES (2016a). Etude de l'Alimentation Totale infantile 2 (EATi) - Tome 2 - Partie 3 : Composés organiques. Rapport d'expertise collective. https://www.anses.fr/fr/system/files/ERCA2010SA0317Ra-Tome2-Part3.pdf

ANSES (2016b). Etude de l'Alimentation Totale infantile 2 (EATi) - Tome 2 - Partie 4 : Résultats relatifs aux résidus de pesticides. Rapport d'expertise collective. https://www.anses.fr/fr/system/files/ERCA2010SA0317Ra-Tome2-Part4.pdf

Armstrong, B., Hutchinson, E., Unwin, J., and Fletcher, T. (2004). Lung cancer risk after exposure to polycyclic aromatic hydrocarbons: A review and meta-analysis, Environ. Health Persp., 112, 970-978.

Baldi, I., Filleul, L., Mohammed-Brahim, B., Fabrigoule, C., Dartigues, J.F., Schwall, S., Drevet, J.P., Salamon, R., and Brochard, P. (2001). Neuropsychologic effects of longterm exposure to pesticides: Results from the French Phytoner study, Environ. Health Persp., 109, 839-844.

Batterman, S., Chen, T.C., Chernyak, S., and Godwin, C. (2009). Design and performance evaluation of a medium flow sampler for airborne brominated flame retardants (BFRs). J. Environ. Monitor., 11(4), 858-866.

Beamer, P.I., Canales, R.A., Ferguson, A.C., Leckie, J.O., and Bradman, A. (2012). Relative pesticide and exposure route contribution to aggregate and cumulative dose in young farmworker children. Int. J. Environ. Res. Public. Health, 9(1), 73-96.

Bekö, G., Weschler, C.J., Langer, S., Callesen, M., Toftum, J., and Clausen, G. (2013). Children's Phthalate Intakes and Resultant Cumulative Exposures Estimated from Urine Compared with Estimates from Dust Ingestion, Inhalation and Dermal 
Blanchard, O., Glorennec, P., Mercier, F., Bonvallot, N., Chevrier, C., Ramalho, O., Mandin, C., and Le Bot, B. (2014). Semivolatile Organic Compounds in Indoor Air and Settled Dust in 30 French Dwellings, Environ. Sci. Technol., 48, 3959-3969.

Blanc-Lapierre, A., Bouvier, G., Garrigou, A., Canal-Raffin, M., Raherison, C., Brochard, P., and Baldi, I. (2012). Chronic central nervous system effects of pesticides : state-ofthe-art, Rev. Epidemiol. Sante., 60(5), 389-400.

Bonvallot, N., Mandin, C., Mercier, F., Le Bot, B., and Glorennec, P. (2010). Health ranking of ingested semi-volatile organic compounds in house dust: an application to France, Indoor Air, 20, 458-472.

Burmaster, D.E., and Hull, D.A. (1997). Using lognormal distributions and lognormal probability plots in probabilistic risk assessments. Hum. Ecol. Risk Assess., 3(2), 235255.

Casas, M., Chevrier, C., Den Hond, E., Fernandez, M. F., Pierik, F., Philippat, C., Slama, R., Toft, G., Vandentorren, S., Wilhelm, M., and Vrijheid, M. (2013). Exposure to brominated flame retardants, perfluorinated compounds, phthalates and phenols in European birth cohorts: ENRIECO evaluation, first human biomonitoring results, and recommendations. Int. J. Hyg. Envir. Heal., 216(3), 230-242.

Duggan, A., Charnley, G., Chen, W., Chukwudebe, A., Hawk, R., Krieger, R.I., Ross, J., and Yarborough, C. (2003). Di-alkyl phosphate biomonitoring data: assessing cumulative exposure to organophosphate pesticides. Regul. Toxicol. Pharmacol., 37(3), 382-395. 
Elbaz, A., Clavel, J., Rathouz, P.J., Moisan, F., Galanaud, J.P., Delemotte, B., Alperovitch, A., and Tzourio, C. (2009). Professional Exposure to Pesticides and Parkinson Disease, Ann. Neurol., 66, 494-504.

Finizio, A., Mackay, D., Bidleman, T., and Harner, T. (1997). Octanol-air partition coefficient as a predictor of partitioning of semivolatile organic chemicals to aerosols, Atmos. Environ., 31, 2289-2296.

Fournier, K., Glorennec, P., and Bonvallot, N. (2014). An exposure-based framework for grouping pollutants for a cumulative risk assessment approach: Case study of indoor semi-volatile organic compounds. Environ. Res., 130, 20-28.

Gaspar, F.W., Castorina, R., Maddalena, R.L., Nishioka, M.G., McKone, T.E., and Bradman, A. (2014). Phthalate Exposure and Risk Assessment in California Child Care Facilities. Environ. Sci. Technol., 48(13), 7593-7601.

Gong, M., Zhang, Y., and Weschler, C.J. (2014). Predicting dermal absorption of gas phase chemicals: transient model development, evaluation, and application, Indoor Air, 24, 292-306.

Helsel, D.R. (2011). Statistics for censored environmental data using Minitab and R (Vol. 77). John Wiley \& Sons.

Helsel, D.R., and Hirsch, R.M. (1992). Statistical methods in water resources (Vol. 49). Elsevier.

Huwe, J.K., Hakk, H., Smith, D.J., Diliberto, J.J., Richardson, V., Stapleton, H.M., and Birnbaum, L.S. (2008). Comparative absorption and bioaccumulation of polybrominated diphenyl ethers following ingestion via dust and oil in male rats. Environ. Sci. Technol., 42(7), 2694-2700. 
IARC (2015a). Polychlorinated biphenyls and polybrominated biphenyls, IARC Monogr. Eval. Carcinog. Risk Chem. Hum., Vol. 107. http://monographs.iarc.fr/ENG/Monographs/vol107/index.php

IARC (2015b). Some organophosphate insecticides and herbicides: diazinon, glyphosate, malathion, parathion, and tetrachlorvinphos, IARC Monogr. Eval. Carcinog. Risk Chem. Hum., Vol.

112. http:// http://monographs.iarc.fr/ENG/Monographs/vol112/index.php

Linares, V., Perelló, G., Nadal, M., Gómez-Catalán, J., Llobet, J. M., and Domingo, J.L. (2010). Environmental versus dietary exposure to POPs and metals: A probabilistic assessment of human health risks. J Env. Monit, 12(3), 681-688.

Lorber, M. (2007). Exposure of Americans to polybrominated diphenyl ethers. J. Expo. Sci. Environ. Epidemiol., 18(1), 2-19.

Mackay, D., Shiu, W.Y., Ma, K.C., and Lee, S.C. (2010a). Handbook of physical-chemical properties and environmental fate for organic chemicals, Vol. 1, Introduction and hydrocarbons. CRC Pressed.

Mackay, D., Shiu, W.Y., Ma, K.C., and Lee, S.C. (2010b). Handbook of physical-chemical properties and environmental fate for organic chemicals, Vol. 2, Halogenated hydrocarbons. CRC Pressed.

Mackay, D., Shiu, W.Y., Ma, K.C., and Lee, S.C. (2010c). Handbook of physical-chemical properties and environmental fate for organic chemicals, Vol. 3, Oxygen containing compounds. CRC Pressed.

Mackay, D., Shiu, W.Y., Ma, K.C., and Lee, S.C. (2010d). Handbook of physical-chemical properties and environmental fate for organic chemicals, Vol. 4, Nitrogen and sulfur 

containing compounds and pesticides. CRC Pressed.

Mandin, C., Mercier, F., Ramalho, O., Lucas, J. P., Gilles, E., Blanchard, O., Bonvallot, N., Glorennec, P., and Le Bot, B. (2016). Semi-volatile organic compounds in the particulate phase in dwellings: A nationwide survey in France. Atmos. Environ., 136, $82-94$.

Mandin C., Mercier F., Lucas J-P., Ramalho O., Blanchard O., Bonvallot N., Raffy G., Gilles E., Glorennec P., and Le Bot B. ECOS-POUSS: A Nationwide Survey of SemiVolatile Organic Compounds in Home Settled Dust. Proceedings of the Indoor Air conference 2014, July 7-12 2014, Hong Kong, Vol. VI, 143-148.

Mitro, S.D., Dodson, R.E., Singla, V., Adamkiewicz, G., Elmi, A. F., Tilly, M. K., Zota, A.R., (2016). Consumer Product Chemicals in Indoor Dust: A Quantitative Meta-analysis of U.S. Studies. Environ. Sci. Technol., 50(19), 10661-10672.

Morrison, G.C., Weschler, C.J., and Bekö, G. (2016). Dermal uptake directly from air under transient conditions: advances in modeling and comparisons with experimental results for human subjects. Indoor air, 26(6), 913-924.

Özkaynak, H., Xue, J., Zartarian, V. G., Glen, G., and Smith, L. (2011). Modeled estimates of soil and dust ingestion rates for children. Risk Anal., 31(4), 592-608.

Pandrangi, L.S., and Morrison, G.C. (2008). Ozone interactions with human hair: Ozone uptake rates and product formation, Atmos. Environ., 42, 5079-5089.

Pelletier, M., Bonvallot, N., Ramalho, O., Blanchard, O., Mercier, F., Mandin, C., Le Bot, B., and Glorennec, P. (2017). Dermal absorption of semivolatile organic compounds from the gas phase: Sensitivity of exposure assessment by steady state modeling to key parameters. Environ. Int., 102, 106-113. 
Raffy G., Mercier F., Glorennec P., Mandin C., and Le Bot B. Human exposure to semivolatile organic compounds (SVOCs) via dust ingestion: a review of influencing factors. Indoor Air conference, 2016. http://www.isiaq.org/docs/Papers/Paper853.pdf

Romero-Franco, M., Hernández-Ramírez, R. U., Calafat, A. M., Cebrián, M. E., Needham, L. L., Teitelbaum, S., Wolff M.S., and López-Carrillo, L. (2011). Personal care product use and urinary levels of phthalate metabolites in Mexican women. Environ. Int., $37(5), 867-871$.

Roosens, L., Cornelis, C., D’Hollander, W., Bervoets, L., Reynders, H., Van Campenhout, K., Van Den Heuvel, R., Neels, H., and Covaci, A. (2010). Exposure of the Flemish population to brominated flame retardants: Model and risk assessment. Environ. Int., 36(4), 368-376.

Roper, C.S., Simpson, A.G., Madden, S., Serex, T.L., and Biesemeier, J.A. (2006). Absorption of [14C]-tetrabromodiphenyl ether (TeBDE) through human and rat skin in vitro. Drug Chem. Toxicol., 29(3), 289-301.

Rostami, I., and Juhasz, A.L. (2011). Assessment of persistent organic pollutant (POP) bioavailability and bioaccessibility for human health exposure assessment: a critical review. Crit. Rev. Env. Sci. Tec., 41(7), 623-656.

Rubin, B.S. (2011). Bisphenol A: An endocrine disruptor with widespread exposure and multiple effects, J. Steroid Biochem., 127, 27-34.

Salthammer, T., and Schripp, T. (2015). Application of the Junge- and Pankow-equation for estimating indoor gas/particle distribution and exposure to SVOCs, Atmos. Environ., $106,467-476$. 
579 Sukiene, V., von Goetz, N., Gerecke, A. C., Bakker, M. I., Delmaar, C. J., \& Hungerbuhler,

580

581

582

583

584

585

586

587

588

589

590

591

592

593

594

595

596

597

598

599

600 K. (2017). Direct and Air-Mediated Transfer of Labeled SVOCs from Indoor Sources to Dust. Environmental Science \& Technology, 51(6), 3269-3277.

Shi, S., and Zhao, B. (2015). Estimating indoor semi-volatile organic compounds (SVOCs) associated with settled dust by an integrated kinetic model accounting for aerosol dynamics. Atmos. Environ., 107, 52-61.

Tamas, G., Weschler, C.J., Bako-Biro, Z., Wyon, D.P., and Strom-Tejsen, P. (2006). Factors affecting ozone removal rates in a simulated aircraft cabin environment, Atmos. Environ., 40, 6122-6133.

Trudel, D., Scheringer, M., von Goetz, N., and Hungerbühler, K. (2011). Total Consumer Exposure to Polybrominated Diphenyl Ethers in North America and Europe. Environ. Sci. Technol., 45(6), 2391-2397.

U.S. EPA (2013). Estimation Program Interface (EPI) Suite (last updated on 15.3.2013, Version EPI 4.11).

U.S. EPA (2011). Exposure Factors Handbook.

U.S. EPA (2005). Guidance on selecting age groups for monitoring and assessing childhood exposures to environmental contaminants. National Center for Environmental Assessment, Washington, DC; EPA/630/P-03/003F. Available from: National Technical Information Service, Springfield, VA, and online at http://epa.gov/ncea.

Weschler, C.J., and Nazaroff, W.W. (2014). Dermal Uptake of Organic Vapors Commonly Found in Indoor Air, Environ. Sci. Technol., 48, 1230-1237.

Weschler, C.J., and Nazaroff, W.W. (2012). SVOC exposure indoors: fresh look at dermal 

pathways, Indoor Air, 22, 356-377.

602 603 604 605 606 607 608 609 610 611

Weschler, C.J., and Nazaroff, W.W. (2010). SVOC partitioning between the gas phase and settled dust indoors, Atmos. Environ., 44, 3609-3620.

Weschler, C.J., and Nazaroff, W.W. (2008). Semivolatile organic compounds in indoor environments, Atmos. Environ., 42, 9018-9040.

Wilson, N.K., Chuang, J.C., Lyu, C., Menton, R., and Morgan, M.K. (2003). Aggregate exposures of nine preschool children to persistent organic pollutants at day care and at home. J. Expo. Anal. Environ. Epidemiol., 13(3), 187-202.

WHO (2006). Principles for Evaluating Health Risks in Children Associated with Exposure to Chemicals. International Programme on Chemical Safety, World Health Organization, Geneva (Environmental Health Criteria 237).

Wormuth, M., Scheringer, M., Vollenweider, M., and Hungerbühler, K. (2006). What Are the Sources of Exposure to Eight Frequently Used Phthalic Acid Esters in Europeans? Risk Anal., 26(3), 803-824.

Zaganas, I., Kapetanaki, S., Mastorodemos, V., Kanavouras, K., Colosio, C., Wilks, M.F., and Tsatsakis, A.M. (2013). Linking pesticide exposure and dementia: What is the evidence? Toxicology, 307, 3-11.

Zhang, X., Yu, Y., Gu, Y., Li, X., Zhang, X., and Yu, Y. (2017). In vitro determination of transdermal permeation of synthetic musks and estimated dermal uptake through usage of personal care products. Chemosphere, 173, 417-424. 

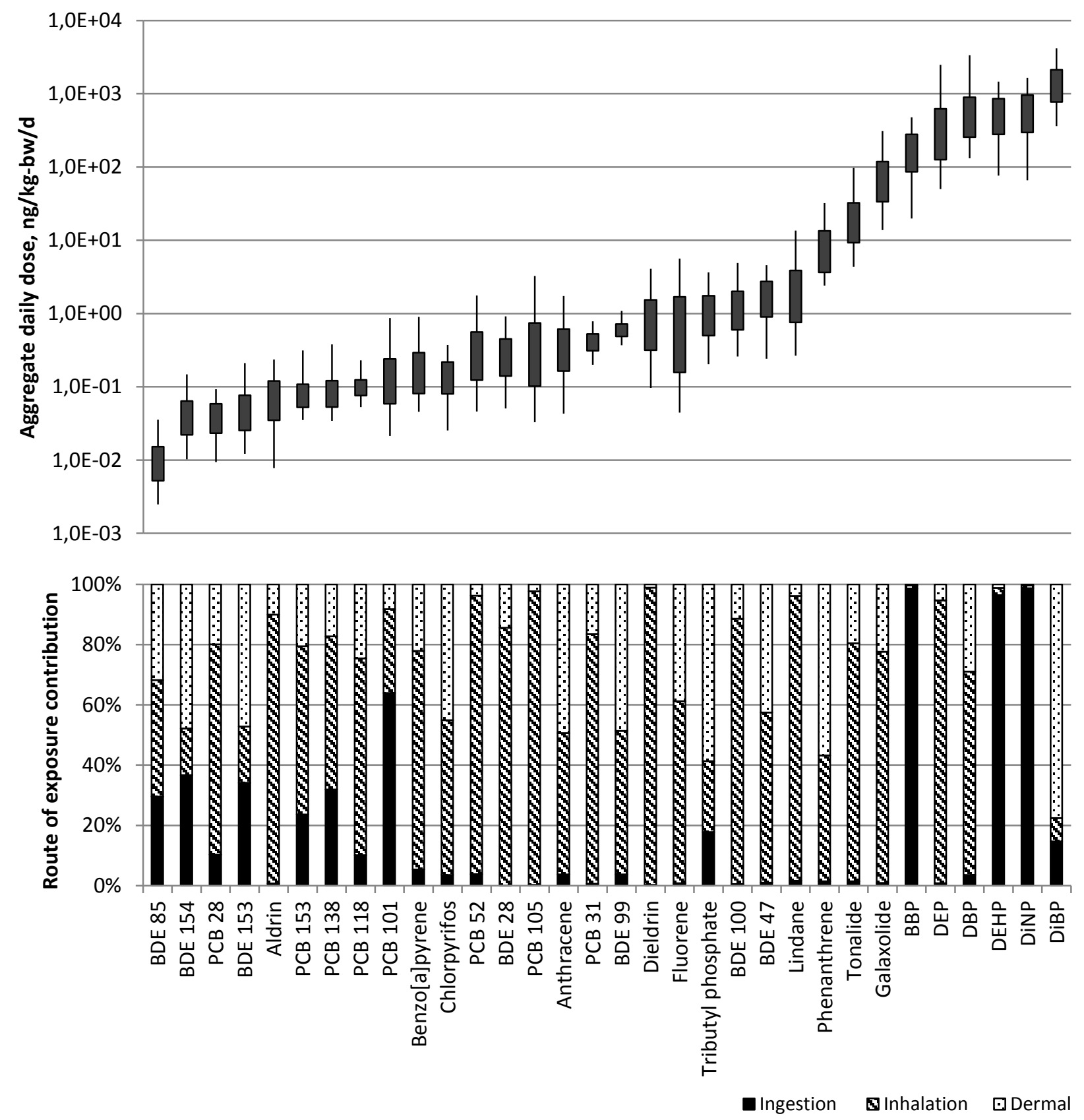

Figure 1. Top panel of the graph shows Aggregate daily dose of each SVOC for a child aged 2 to 3 years (ng/kg-bw/d), percentiles $5^{\text {th }}, 25^{\text {th }}, 75^{\text {th }}$ and $95^{\text {th }}$ are presented in box plot format. The bottom panel of the graph shows the contribution made by each route of exposure (ingestion, inhalation and dermal exposure from air) to total indoor exposure, based on the median value estimated for each SVOC for children aged 2 to 3 years (ng/kg-bw/d). 


\begin{tabular}{|c|c|c|c|c|c|c|c|c|}
\hline \multirow{2}{*}{ SVOC } & \multicolumn{8}{|c|}{ Relative contribution (\%) } \\
\hline & [10-20] & [20-30] & [30-40] & {$[40-50]$} & {$[50-60]$} & [60-70] & {$[70-80]$} & [80-90] \\
\hline Fluorene & & & & & & & & Cgas \\
\hline DEP & Cdust & fpulm & & & Cgas & & & \\
\hline Anthracene & & & & & & & & Cgas \\
\hline Phenanthrene & Cdust & & & & & & Cgas & \\
\hline PCB 28 & & & fpulm & Cgas & & & & \\
\hline PCB 31 & & fpulm & & & Cgas & & & \\
\hline Tonalide & & fpulm & & Cpart & & & & \\
\hline Aldrin & & & fpulm & & Cgas & & & \\
\hline Dieldrin & & & fpulm & & Cpart & & & \\
\hline Galaxolide & & fpulm Cgas & Cpart & & & & & \\
\hline Tributylphosphate & & & & & & & Cgas & \\
\hline DiBP & & Cdust & & & & Cgas & & \\
\hline PCB 52 & Cdust & fpulm & & & Cpart & & & \\
\hline DBP & & fpulm & & & Cpart & & & \\
\hline Lindane & fpulm $\quad H$ & Cpart & Cgas & & & & & \\
\hline Chlorpyrifos & & fpulm & & & Cgas & & & \\
\hline BBP & Cpart & & & & Cdust & & & \\
\hline PCB 101 & Cgas & & & & & Cdust & & \\
\hline BDE 28 & fpulm & Cpart & & Cgas & & & & \\
\hline PCB 138 & & Cgas & & & & Cdust & & \\
\hline PCB 153 & & & Cgas & Cdust & & & & \\
\hline PCB 118 & & Cdust & & & Cgas & & & \\
\hline PCB 105 & fpulm & & & & & Cpart & & \\
\hline BDE 47 & & & & & & & & Cgas \\
\hline Benzo[a]pyrene & & & & & & & & Cpart \\
\hline BDE 99 & & Kow & $\mathbf{H}$ & & & & & \\
\hline BDE 85 & & & & & & & Cgas & \\
\hline BDE 100 & fpulm & & & & & Cpart & & \\
\hline BDE 153 & Cdust & & & & & Cgas & & \\
\hline DEHP & fdust & & & & & Cdust & & \\
\hline BDE 154 & & Cdust & & & & Cgas & & \\
\hline DiNP & & & fdust & Cdust & & & & \\
\hline
\end{tabular}

630 Figure 2. Relative contribution (\%) of key parameters $\left(\mathrm{C}_{\mathrm{gas}}, \mathrm{C}_{\mathrm{par}}, \mathrm{C}_{\text {dust }}, \mathrm{f}_{\text {pulm }}, \mathrm{f}_{\text {dust }}, \log \left(\mathrm{K}_{\mathrm{ow}}\right)\right.$ 631 and $\mathrm{H}$ ) to total variation of Aggregate daily doses from exposures to 32 indoor SVOCs 632 (ng/kg-bw/d) for children aged 2 to 3 years. Only relative contributions above $10 \%$ are 633 represented. Bold font indicates the more influential parameter for each SVOC. Compounds 634 are ranked according to their volatility (based on their $\log \left(\mathrm{K}_{\mathrm{oa}}\right)$ values) from the most volatile 635 (fluorene) to the least volatile (DiNP). 


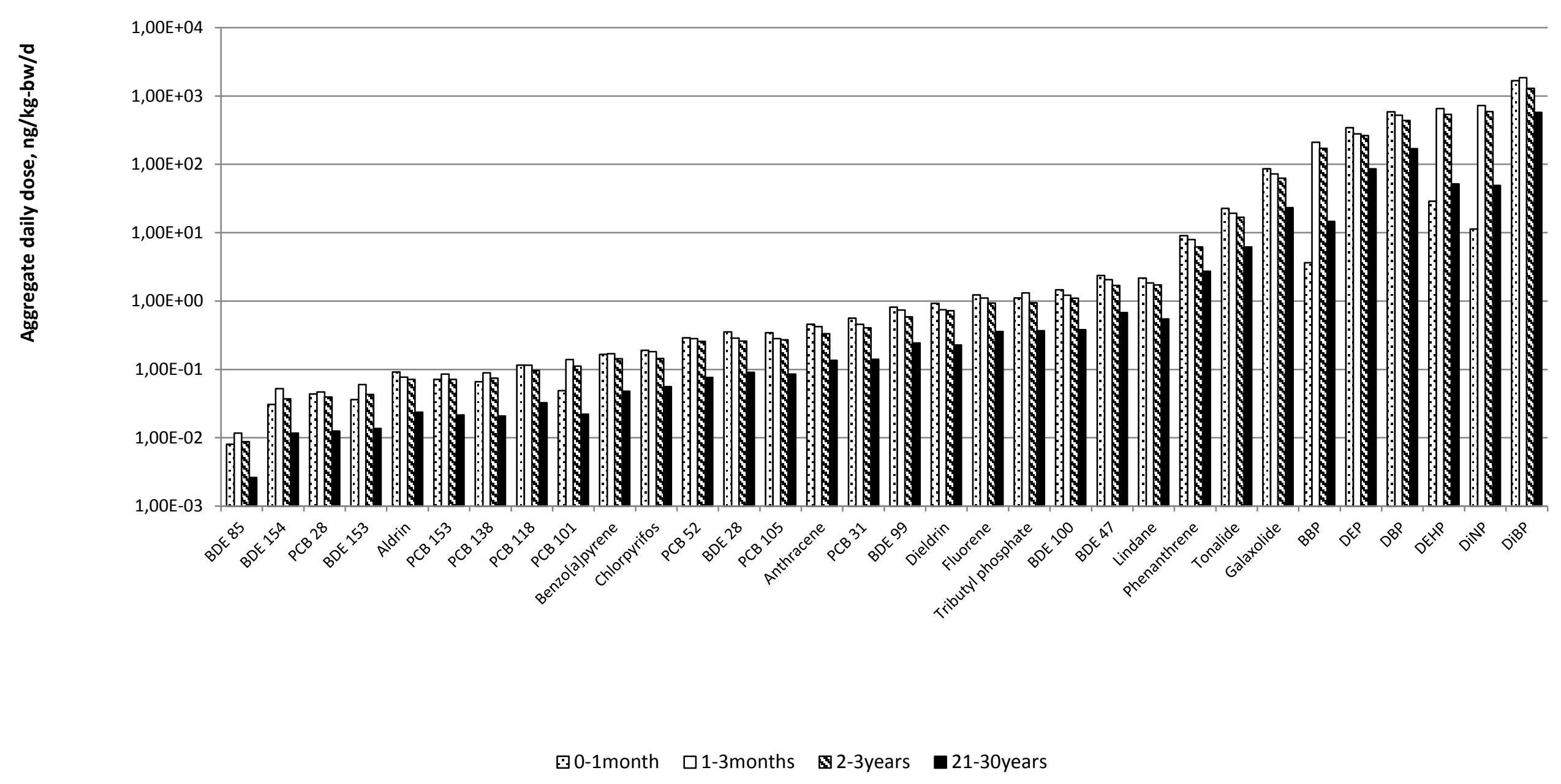

Figure 3. Aggregate daily dose of each SVOC for four age groups (ng/kg-bw/d). 